\title{
The Relationship Between Attitudes about Research and Health Literacy among African American and White (Non-Hispanic) Community Dwelling Older Adults
}

\author{
Anjali Shah ${ }^{1} \cdot$ Christiana Macauley ${ }^{2} \cdot$ Liang Ni $^{3} \cdot$ Allison A. Bay $^{3} \cdot$ Madeleine E. Hackney $^{3,4,5,6,7}$ (I) \\ Received: 15 September 2020 / Revised: 7 November 2020 / Accepted: 23 November 2020 / Published online: 7 January 2021 \\ (C) This is a U.S. government work and its text is not subject to copyright protection in the United States; however, its text may be subject to foreign copyright \\ protection 2021
}

\begin{abstract}
Background Ethnic minority representation lacks in research. Understanding factors that promote minorities in research helps address this participation gap. Minorities often face representation disparities, including health education, socioeconomic status, and race. Compared to other races in the USA, over 50\% of African Americans (AA) over age 65 face obstacles towards achieving basic health literacy skills. This study aims to investigate differences in beliefs regarding research and health literacy between White and AA participants.

Methods This cross-sectional study compared 46 AA vs. 60 White healthy older adults $(n=106$; age $=73.97 \pm 10.6$ years $)$. Participants were assessed once with the Participant Attitudes and Beliefs towards Research Questionnaire (PABRQ) and two validated health literacy measures, the Rapid Estimate of Adult Literacy in Medicine (REALM) and the Short Test of Functional Health Literacy for Adults (S-TOFHLA).

Results Controlling for age, sex, and education, AA performed significantly worse on REALM. Compared to White participants, AA more likely believed that researchers were motivated to perform studies to increase their general knowledge. Participants with lower health literacy scores more likely believed that scientists were motivated to conduct research to minimize treatment expenses. About $83-85 \%$ of participants reported not being familiar with the informed consent process, $90-95 \%$ had positive attitudes towards research involvement, and 38-52\% believed researchers performed to promote their own careers.

Conclusion This work helps link older adults' beliefs towards research, health literacy, and their participation in research. Future research is needed to remove barriers to participation in research for underserved, older adults.
\end{abstract}

Keywords Health literacy $\cdot$ Beliefs $\cdot$ Attitudes $\cdot$ Minorities $\cdot$ Older adults $\cdot$ Representation

\section{Introduction}

Although the aging population in the USA is increasingly diverse, minority and low-income groups of older adults are historically and currently remain the least

Madeleine E. Hackney

mehackn@emory.edu; madeleine.hackney@va.gov

1 Emory College of Arts and Sciences, Atlanta, GA, USA

2 Emory University Rollins School of Public Health, Atlanta, GA, USA

3 Department of Medicine, Division of Geriatrics and Gerontology, Emory University School of Medicine, Atlanta, GA, USA represented in research [1]. As researchers design and apply methodology and scientific inquiry to increase awareness among participant communities, it is essential that all racial/ethnic demographic groups are represented sufficiently in data collections. 


\section{Minority Race and Age as Determinants of Health Status}

Poor socioeconomic status, lower educational attainment, and race as a minority have all been linked to adversely influence health outcomes [2]. Poverty and socioeconomic status across racial groups are major contributors to racial disparities in health [3]. Racial minorities of low socioeconomic status often adopt unhealthy behaviors due to financial hardship, which prevents the access to effective healthcare, such as regular preventive medical checkups and screenings [4]. Additionally, mounting evidence based primarily on the health experiences of African Americans (AA) and Whites indicates that racial differences in morbidity and mortality are tied to an inequity in access to resources, such as educational attainment [5]. Educational outcomes for minority groups are often a function of varying access to key resources, like quality curriculum, based on diminished social status [6]. Quality curriculum often includes health education, defined as learning experiences that are designed to help communities and individuals improve their health by increasing their knowledge [7]. Additionally, health education curriculum often includes modules designed to improve health literacy, which helps patients manage their own health decisions.

\section{Minority Race and Age as Determinants of Health Literacy}

Health literacy, the extent to which individuals can conceptualize basic health information and services to make their own appropriate health decisions, plays a role in improving an individual's health [7]. Since health literacy is tied to health outcomes and racial minorities often experience worse health outcomes, it is perhaps unsurprising that racial differences exist in persons with average health literacy levels [8, 9]. Approximately $24 \%$ of AA and $41 \%$ of Hispanic adults exhibit "below basic" health literacy compared to $9 \%$ of White adults, as measured by the National Assessment of Adult Literacy (NAAL) [10]. The assessment provides the health literacy status for American adults, ages 16 and older, with categorized literacy performance (below basic, basic, intermediate, proficient). Adults who score "below basic" performance have elementary literacy skills, ranging from nonliterate in English to being able to easily locate identifiable information in short, commonplace prose [11].

In addition to race, age is an important factor in health literacy levels. Unfortunately, health literacy challenges may impact older adults more than other age groups. Many adults who are aged 65 years and older in the USA lack basic health literacy skills required to self-manage their health in comparison to younger individuals [12]. These health literacy skills are significant, as consequences of limited health literacy are linked with higher incidences of chronic illness, poorer self-reported health, lower utilization of preventive health services, and higher healthcare costs [13]. Fortunately, health literacy is in fact modifiable [14]. Health literacy acts as a modifiable determinant of health behavior and can affect disease prevention, as health literacy and health status are associated in patients undergoing prevention treatments [15]. Due to the modifiable uses of health literacy, programs targeting health literacy can benefit from improved outcomes in older, disadvantaged adults.

\section{Minority Race and Age as Determinants of Research Participation}

\section{Individual Factors}

Factors that contribute to poor health literacy are based on both individual and community-based barriers. Individual factors associated with low health literacy include modifiable healthcare access barriers that are both lingual and educational $[16,17]$.

In the USA, $43 \%$ of adult learners have stated that English exists as their second language, resulting in limited English proficiency [18]. Language barriers can result in limited health literacy. For example, differences in language and word meanings can lead to misinterpretation of information and therefore functional poor health literacy. Adults who speak a language besides English before starting school often have lower health literacy than those who spoke only English before starting school [19].

Education is another individual factor that presents a barrier to health literacy for many. While the educational attainment of all races has increased over the past decade in the USA, a gap remains between races, especially among those with a bachelor's degree or higher. Approximately $22.5 \%$ of AA and $15.5 \%$ of Hispanics have earned a full four-year college degree compared to $36.2 \%$ of Whites [20]. Without postsecondary education due to socioeconomic status challenges, these minority groups are at risk for poor health literacy.

\section{Community Factors}

Community factors that lead directly or indirectly to poor health literacy outcomes in minority groups include lack of healthcare literacy material written in "simpler" language, lack of educational interventions tailored specifically for minority groups, and minority participants' inability to understand health jargon due to historical marginalization in science [6]. Minority communities face several barriers to participating in clinical research studies, which could potentially improve the health of these individuals. Minority communities have shown reluctance to participate in potentially beneficial research for many reasons, often well founded in unfortunate historical events (e.g., Tuskegee syphilis trials). Barriers to participation in research, noted from focus groups conducted by Perkins et al. [21] with diverse older adults, include perceived ageism and disrespect from health professionals and distrust of 
researchers and the medical community. Additional community barriers include time constraints [22], the perception that there is no real-time benefit to participants, lack of awareness of research assessments tested [23], and inadequate knowledge concerning the need for medical research [24].

\section{Research Participation Affects Participants' Health Outcomes}

Increased participation in research for seniors has improved health outcomes [25]. Inclusion of diverse research participants who vary in race, ethnicity, gender, and age generalizes study results, advances medical enhancements of effective therapies, and promotes underrepresented populations to experience benefits of research innovations and become recipients of high-quality care [26]. Increased research participation from informed older adults who range across multiple racial, ethnic, and socioeconomic status helps researchers better characterize the various healthcare challenges that older adults face, resulting in decreased burden and cost to the healthcare systems and an overall better health outcome for underrepresented, older patients [27].

\section{The Present Study}

We investigated representation disparities in medical research by examining the attitudes towards participation in research programs and differences in health literacy performance measures between AA and White caregivers to analyze if poorer performance influences beliefs towards research. Our theoretical framework for this study is based on the socio-ecological model developed by Bronfenbrenner [28] (Fig. 1). The study addresses the multifaceted factors of the model from research policies including protection of research subjects to individual factors, such as health literacy and beliefs about research. Therefore, this study aims to answer the following questions: Are there differences in health literacy performance between the participants? Are there differences in beliefs towards research participation between both groups? and Is poorer health literacy associated with less favorable beliefs with participating in research? We hypothesized that AA participants would perform worse on health literacy measures and have more negative beliefs towards research than White participants. We hypothesized that participants with lower health literacy scores would be less likely to have positive beliefs towards research participation.

\section{Materials and Methods}

This study was reviewed and approved by the Emory University Institutional Review Board under protocol \#80676. All participants provided written informed consent prior to participation.
Fig. 1 Socio-ecological theoretical model, based on Bronfenbrenner's model (1977), illustrating multifaceted and interactive effects of personal and environmental factors that influence research participation and health literacy of minority, aging adults

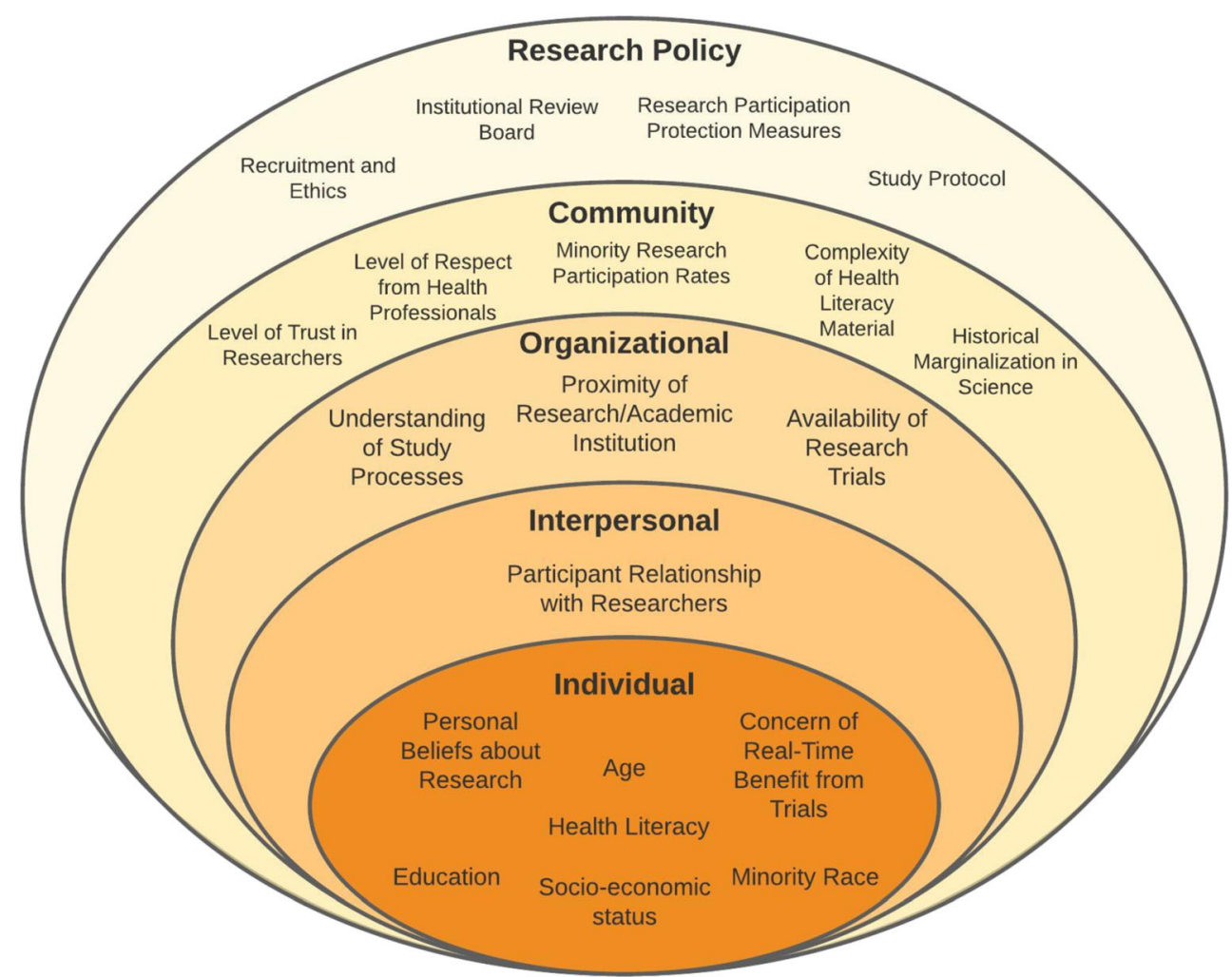




\section{Participants}

Adults ages 55 years and older were recruited from the Atlanta metro area, aided by community partner organizations, ensuring robust representation of distinct ethnic and socioeconomic strata. Partner organizations included senior living communities at high, moderate, and low-income levels; a volunteer organization associated with an Emory community servicelearning program [29]; and an older adult education organization. Cross-sectional, secondary analyses were performed on baseline data, and participants diagnosed with Parkinson's disease were excluded, as only care partners were analyzed. A total of 106 people was included, and race was stratified by AA $(n=46)$ versus White, non-Hispanic $(n=60)$ participants. Analysis was restricted to AA and White respondents because the level of participation from other racial groups was not substantial $(<1 \%)$ for robust analysis. Dillard et al. [30] examines a similar sample of participants but does not examine differences between AA and White individuals.

\section{Measures}

Participants completed demographic and health characteristics surveys prior to the study with a questionnaire.

Health literacy was evaluated with the Rapid Estimate of Adult Literacy in Medicine (REALM) and the Short Test of Functional Health Literacy for Adults (S-TOFHLA). REALM is a 66-item word recognition test to identify risk for poor literacy skills [31]. REALM associates the numerical raw score of correctly pronounced words to the patients' reading levels: third grade and below (0-18), fourth to sixth grade (19-44), seventh to eighth grade (45-60), and high school (61-66). S-TOFHLA is a seven-minute reading comprehension test to assess comprehension of health-related material and is divided into inadequate (0-16), adequate (17-22), and functional (23-36) categories [32].

Research beliefs were assessed by the Participant Attitudes and Beliefs towards Research Questionnaire (PABRQ), an instrument based on questionnaires from Madsen et al. [33] and used in Dillard et al.'s study [30] to assess respondents' attitudes towards medical research (six items) and comprehension of doctors' motives to conduct medical research (five items). We supplemented two items regarding self-reported knowledge of informed consent processes and research subject protection measures and two items about previous research participation in the questionnaire. The questions have categorical answer choices. For all questions except two (Q3 and Q4), the response was assessed via a numerical point scale where higher and lower numbers were associated with positive and negative responses, respectively. Q3 and Q4 were assessed with a "yes/no" response. Based on the distribution of responses on the PABRQ, the answers to each question were dichotomized for statistical analysis. Questions 1 and 2 were presented on a five-point Likert scale $(1=$ not at all/ negative; 2 = barely/generally negative, but necessary; $3=$ neutral/positive but with reservations; $4=$ quite a bit $/$ positive; $5=$ a lot/very positive), and they were dichotomized into two categories: generally familiar $(3,4,5)$ vs. not familiar $(1,2)$. Question 5 was also presented on a five-point scale ranging in level ( $1=$ negative; $2=$ negative, but necessary; $3=$ positive with reservations; $4=$ positive; $5=$ very positive) and were dichotomized into positive $(4,5)$ and positive with reservations (3) categories. Questions 3 and 4 are split by "yes/no" answer choices, whereas questions 6-9 have threepoint scales ( $1=$ negative; $2=$ hesitant; $3=$ positive) dichotomized into two categories for analysis: negative and positive. Question 10 is on a four-point scale $(1=$ never; $2=$ not always but sometimes; $3=$ most of the time; $4=$ always) and was dichotomized into always (4) and never or sometimes $(1,2,3)$ categories. Lastly, questions 11A-E have four-point answer choices $(1=$ not important; $2=$ minor importance; $3=$ important; 4 = very important) and were dichotomized into importance and unimportance.

\section{Statistical Analysis}

Descriptive statistics were calculated and compared between $\mathrm{AA}$ and White participant groups using Chi-square tests for categorical variables and independent $t$ tests for continuous variables. Spearman correlations were used to determine associations between scores on measures of health literacy (REALM and S-TOFHLA) and scores on the PABRQ. Only a select number of items were analyzed from PABRQ rather than the entire question set when examining correlations. Cohen's conventions were used to determine the strength of association, where 0.1 is small, 0.3 is moderate, and 0.5 is large.

A logistic regression model controlling for age, sex, and education was used to analyze differences between groups on beliefs about research, using the dichotomized values from the PABRQ (see Measures above).

Health literacy performance was analyzed with a linear regression model adjusted for age, sex, and education variables. The $\alpha$ level was set at 0.05 for all tests. All analyses were carried out using R software (version 1.2.1335).

\section{Results}

\section{Demographics}

A cohort of 106 healthy older adults were included in this study (age $=73.97 \pm 10.6$ years; AA, $n=46$; White, $n=60$ ): Descriptive clinical characteristic and demographic statistics of the sample are summarized in Table 1. Participants did not differ significantly in number of comorbidities, amount of medications taken, number of falls in the past year, use of an 
Table 1 Characteristics of the sample including African American vs. White individuals

\begin{tabular}{|c|c|c|c|c|}
\hline & $\begin{array}{l}\text { Total sample } \\
(n=106) \\
\text { Mean } \pm \mathrm{SD} / N(\%)\end{array}$ & $\begin{array}{l}\text { African American (AA) } \\
(n=46) \\
\text { Mean } \pm \mathrm{SD} / N(\%)\end{array}$ & $\begin{array}{l}\text { White } \\
(n=60) \\
\text { Mean } \pm \mathrm{SD} / N(\%)\end{array}$ & $P$ values \\
\hline Age $^{\mathrm{a}}$ (years) & $73.97 \pm 10.6$ & $68.24 \pm 9.1$ & $78.44 \pm 9.6$ & $<0.001 *$ \\
\hline Education $^{\mathrm{a}}$ (years) & $15.83 \pm 2.2$ & $15.24 \pm 2.1$ & $16.28 \pm 2.1$ & $0.017 *$ \\
\hline Number of comorbidities ${ }^{\mathrm{a}}$ & $2.79 \pm 2.1$ & $2.74 \pm 2.3$ & $2.82 \pm 1.9$ & 0.864 \\
\hline Number of medications ${ }^{\mathrm{a}}$ & $3.55 \pm 3.2$ & $2.9 \pm 2.7$ & $4.09 \pm 3.5$ & 0.086 \\
\hline Number of falls in the past year ${ }^{\mathrm{a}}$ & $0.8 \pm 2.7$ & $0.51 \pm 1.8$ & $1.02 \pm 3.2$ & 0.351 \\
\hline $\mathrm{Sex}^{\mathrm{b}}, n(\%)$ & & & & $0.049 *$ \\
\hline $\begin{array}{l}\text { Men } \\
\text { Women }\end{array}$ & $\begin{array}{l}30(28.3) \\
76(71.6)\end{array}$ & $\begin{array}{l}8(17.4) \\
38(82.6)\end{array}$ & $\begin{array}{l}22(36.7) \\
38(63.6)\end{array}$ & \\
\hline Use of assistive device ${ }^{\mathrm{b}}, n(\%)$ & & & & 0.052 \\
\hline $\begin{array}{l}\text { No } \\
\text { Yes }\end{array}$ & $\begin{array}{l}69(66.3) \\
35(33.7)\end{array}$ & $\begin{array}{l}35(77.8) \\
10(22.2)\end{array}$ & $\begin{array}{l}34(57.6) \\
25(42.4)\end{array}$ & \\
\hline Occupation status $^{\mathrm{b}}, n(\%)$ & & & & 0.158 \\
\hline $\begin{array}{l}\text { Employed } \\
\text { Homemaker } \\
\text { Not employed }\end{array}$ & $\begin{array}{l}21(20.2) \\
4(3.8) \\
79(76)\end{array}$ & $\begin{array}{l}8(17.8) \\
0(0) \\
37(82.2)\end{array}$ & $\begin{array}{l}13(22) \\
4(6.8) \\
42(71.2)\end{array}$ & \\
\hline
\end{tabular}

Values are mean \pm SD unless otherwise noted

a Two-tailed, independent $t$ tests were used for continuous variables, comparing AA and White groups

${ }^{\mathrm{b}}$ Chi-square test was used for categorical variables

* $P$ values indicate significant differences between AA and White groups at the 0.05 level

assistive device for walking (cane, walker, etc.), or occupational status. AA and White participants were statistically significant on age, education, and sex. Due to the differences between groups, these variables were controlled for in the subsequent regression analysis.

\section{Health Literacy Performance Outcomes}

Linear regression, which controlled for age, sex, and education, compared mean differences between AA and White groups on health literacy, expressed as standardized betas, with AA participants as the reference group. On the REALM total score (/66), AA participants performed significantly poorer compared to White participants (AA: $59.59 \pm$ 9.9; Whites: $64.73 \pm 3.1 ; B=4.76 ; \beta=0.32 ; p<.001)$. On STOFHLA total score (/36), AA participants performed similarly to White participants (AA: $32.33 \pm 5.6$; Whites: $33.1 \pm$ $5.8, B=1.62 ; \beta=0.14 ; p=.174)$.

\section{Association Between Health Literacy and Research Participation Beliefs}

Q11C, which asked "To what extent is the wish to minimize total expenses in treatment/examination important?", was significantly and negatively correlated $(r=-0.23)$ with health literacy $(p<0.05)$, showing that those with poorer health literacy, as per REALM scores, tended to believe scientists were motivated to conduct clinical research to minimize total expenses in treatment/examination. Q6 asked participants what their attitude was towards having themselves participate in research and was found to have a nearly significant and positive correlation $(r=0.21)$ with health literacy ( $p=$ 0.073), suggesting that those with higher REALM scores had more positive attitudes towards their own participation in research. Nonsignificant, weak correlations $(r=0.03-$ 0.20 ) between health literacy and research beliefs were observed for all other belief items (Table 2).

\section{Research Participation Beliefs}

Most participants (83-85\%) were not familiar with the informed consent process, even though 55-70\% of participants were generally familiar with research subject protection measures. Furthermore, $68 \%$ of AA participants and $63 \%$ of White participants had been previously asked to participate in research. Slightly more than half of our participants had participated in research before (53-56\%). Most participants (74-86\%) had a positive attitude but with reservations towards research with human participants while $14-26 \%$ of participants had a positive attitude. Additionally, an overwhelming majority of participants had positive attitudes towards participating in research themselves (94-95\%) or a family member or close friend participating in research $(90 \%)$. Attitude towards random assignment was positive in general; however, a greater percentage of AAs ( $71 \%$ ) had positive attitudes versus only $56 \%$ of White participants. Positive and negative 
Table 2 Correlation matrix between PABRQ items and health literacy ${ }^{\mathrm{a}}$

\begin{tabular}{|c|c|c|c|}
\hline $\begin{array}{l}\text { Beliefs } \\
\text { Characteristics }^{\mathrm{c}}\end{array}$ & & $\begin{array}{l}\text { REALM total } \\
\text { score }(/ 66)^{\mathrm{b}}\end{array}$ & $\begin{array}{l}\text { S-TOFHLA total } \\
\text { score }(/ 36)^{\mathrm{b}}\end{array}$ \\
\hline \multirow{2}{*}{$\begin{array}{l}\text { Q1^: Familiarity with informed consent processes? }(5 \text { point scale }) \\
\quad(1=\text { not at all/negative; } 2=\text { barely/generally negative, but necessary; } \\
3=\text { neutral/positive but with reservations; } 4 \text { = quite a bit/positive; } 5=\text { a } \\
\text { lot/very positive })\end{array}$} & Correlation & -0.03 & 0.13 \\
\hline & $P$ value & 0.828 & 0.277 \\
\hline \multirow{2}{*}{$\begin{array}{l}\text { Q2: Familiarity with research subject protection measures? }(5 \text { point scale }) \\
\qquad \begin{array}{l}\text { (1= not at all/negative; } 2=\text { barely/generally negative, but necessary; } \\
3=\text { neutral/positive but with reservations; } 4=\text { quite a bit/positive; } \\
5=\text { a lot/very positive) }\end{array}\end{array}$} & Correlation & 0.05 & 0.12 \\
\hline & $P$ value & 0.695 & 0.331 \\
\hline \multirow{2}{*}{$\begin{array}{l}\text { Q3: Were you ever asked to participate in research? } \\
\text { (2 point scale) }(0=\text { no; } 1=\text { yes })\end{array}$} & Correlation & 0.15 & 0.05 \\
\hline & $P$ value & 0.194 & 0.677 \\
\hline \multirow[t]{2}{*}{ Q4: Have you ever participated in research? ( 2 point scale) $(0=$ no; $1=$ yes $)$} & Correlation & 0.20 & 0.03 \\
\hline & $P$ value & 0.09 & 0.797 \\
\hline \multirow{2}{*}{$\begin{array}{l}\text { Q5: Attitude towards research with human participants? }(5 \text { point scale }) \\
\qquad(1=\text { negative; } 2=\text { negative, but necessary; } 3=\text { positive with reservations; } \\
4=\text { positive; } 5=\text { very positive })\end{array}$} & Correlation & 0.10 & -0.14 \\
\hline & $P$ value & 0.399 & 0.228 \\
\hline \multirow{2}{*}{$\begin{array}{l}\text { Q6: Attitude towards participating in research yourself? ( } 3 \text { point scale) } \\
\qquad(1=\text { negative; } 2=\text { hesitant; } 3=\text { positive })\end{array}$} & Correlation & 0.21 & 0.1 \\
\hline & $P$ value & 0.073 & 0.414 \\
\hline \multirow{2}{*}{$\begin{array}{l}\text { Q7: Attitude towards someone in family/close friend participating in } \\
\text { human research? ( } 3 \text { point scale })(1=\text { negative; } 2=\text { hesitant; } 3=\text { positive })\end{array}$} & Correlation & 0.16 & -0.14 \\
\hline & $P$ value & 0.186 & 0.26 \\
\hline \multirow{2}{*}{$\begin{array}{l}\text { Q8: Attitude towards random assignment? ( } 3 \text { point scale) }(1=\text { negative; } \\
2=\text { hesitant; } 3=\text { positive) }\end{array}$} & Correlation & -0.03 & -0.13 \\
\hline & $P$ value & 0.806 & 0.279 \\
\hline \multirow{2}{*}{$\begin{array}{l}\text { Q9: Opinion of participants being assigned to treatment vs. non-treatment? ( } 3 \text { point scale })(1=\text { negative; } \\
2=\text { hesitant; } 3=\text { positive })\end{array}$} & Correlation & 0.05 & -0.17 \\
\hline & $P$ value & 0.696 & 0.157 \\
\hline \multirow{2}{*}{$\begin{array}{l}\text { Q10: Is it necessary to examine "new" drugs using science/experiments before they are implemented? } \\
\text { ( } 4 \text { point scale) }(1=\text { never; } 2=\text { not always but sometimes; } \\
3=\text { most of the time; } 4=\text { always })\end{array}$} & Correlation & 0.00 & -0.14 \\
\hline & $P$ value & 0.996 & 0.239 \\
\hline \multicolumn{4}{|l|}{$\begin{array}{l}\text { Q11: What motives do you think scientists have to conduct medical/clinical research } \\
\text { (a-e): (4-point scale) }(1=\text { not important; } 2=\text { minor importance; } 3=\text { important; } 4=\text { very important })\end{array}$} \\
\hline \multirow[t]{2}{*}{ 11.a: The wish to find new treatments/examinations? } & Correlation & 0.06 & -0.12 \\
\hline & $P$ value & 0.644 & 0.336 \\
\hline \multirow[t]{2}{*}{ 11.b: The wish to help patients? } & Correlation & -0.15 & -0.09 \\
\hline & $P$ value & 0.203 & 0.471 \\
\hline \multirow[t]{2}{*}{ 11.c: The wish to minimize total expenses in treatment/examination? } & Correlation & -0.23 & -0.11 \\
\hline & $P$ value & $0.049^{*}$ & 0.365 \\
\hline \multirow[t]{2}{*}{ 11.d: The wish to promote their own career? } & Correlation & 0.10 & -0.05 \\
\hline & $P$ value & 0.382 & 0.691 \\
\hline \multirow[t]{2}{*}{ 11.e: The wish to increase knowledge generally? } & Correlation & -0.14 & -0.17 \\
\hline & $P$ value & 0.229 & 0.152 \\
\hline
\end{tabular}

${ }^{\text {a }}$ Only select items from PABRQ are included rather than all questions

${ }^{\mathrm{b}}$ Values are Spearman correlation coefficients

${ }^{\mathrm{c}}$ Correlation scores are based on the frequency of how participants responded to each question on PABRQ via the actual numerical point scales (higher numbers on scale represent more positive values)

* $P$ values indicate significant correlations at the 0.05 level

${ }^{\wedge}$ Questions 1 and 2 were presented on a five-point Likert scale $(1=$ not at all/negative; 2 = barely/generally negative, but necessary; $3=$ neutral/positive but with reservations; $4=$ quite a bit/positive; $5=$ a lot/very positive), Question 5 was presented on a five-point scale ranging in level $(1=$ negative; $2=$ negative, but necessary; $3=$ positive with reservations; $4=$ positive; $5=$ very positive), Q $6-9$ have three-point scales $(1=$ negative; $2=$ hesitant; $3=$ positive), Question 10 is on a four-point scale $(1=$ never; $2=$ not always but sometimes; $3=$ most of the time; $4=$ always $)$. Questions $11 \mathrm{~A}-\mathrm{E}$ have fourpoint answer choices $(1=$ not important; 2 = minor importance; 3 = important; 4 = very important $)$ 
opinions about participants assigned to treatment versus nontreatment were split across both groups. Most participants (69-71\%) also believed that it is not necessary to examine "new" drugs before they are implemented in science experiments or treatments. When patients were asked what motivates scientists to conduct medical/clinical research, more than $3 / 4$ of participants stated that they think scientists are motivated to find new treatments and examinations (77$86 \%$ ), to help patients (74-77\%), to reduce total expenses of treatments $(61-71 \%)$, and to increase knowledge generally (60-77\%). Lastly, fewer (38-52\%) of the participants thought the wish to promote the scientist's own career was motivating to the scientist.

A significant finding between groups was that more AA participants believed that scientists are motivated to perform research to increase general scientific knowledge than White participants $(77 \%$ versus $60 \%, p=0.024)$, on Q11E, when controlling for age, sex, and education (Table 3 ).

\section{Discussion}

The present study examined the relationship between AA and White older adults on measures of health literacy and their beliefs regarding participation in research. We also examined whether poorer health literacy engendered less favorable attitudes towards research. After controlling for age, sex, and education, we observed that AAs performed significantly worse on the REALM literacy test compared to White participants. However, we cannot conclude that AAs have more negative beliefs towards research than White participants because our results showcase only one significant difference: AAs believed that scientists perform science for the motive of increasing general scientific knowledge more than White participants. We also predicted that participants with lower health literacy scores would be less likely to have positive beliefs towards research participation. Negative correlations of moderate effect size were observed between poorer health literacy and the extent to minimize total expenses in treatments or examinations. Positive correlations of moderate effect size were observed between better health literacy and a positive attitude for participants to participate in research. Weak effect sizes with no significant associations for other variables were investigated, thus refuting our hypothesis that a strong correlation exists. Although the majority of our sample had favorable attitudes towards research, including participating themselves, many also had some reservations towards human research. These reservations could be due to the participants' lack of fully understanding the potential rights they have in research involving human participants [34]. Some 1/3 to $1 / 2$ of participants thought that scientists were mostly motivated to promote their own careers.
We predicted that AA would have negative attitudes towards research in comparison to White participants. This prediction was not observed. However, the more positive belief that scientists desire to increase general scientific knowledge was observed in AA compared to Whites. This may stem from AA's gaps in knowledge about scientific concepts, such as involvement in clinical research, due to underrepresentation of Blacks in the STEM (science, technology, engineering and mathematics) workforce [35]. Therefore, AA participants perhaps thought scientists would want to learn significantly more general knowledge through their studies in comparison to White participants.

AA performed significantly worse on the REALM literacy test compared to White caregivers; however, no significant performance differences were observed with STOFHLA. REALM focuses primarily on pronunciation and recognition of medical terminology. Perhaps the large performance difference between racial groups in REALM is associated with unmeasured cultural, language, and socioeconomic covariates $[36,37]$. S-TOFHLA, on the other hand, focuses on narrative text comprehension and no significant performance differences between groups were noted, which may be an indication that such covariates are not associated with the literacy test.

Our results show interesting, though nonsignificant findings, as most participants are generally familiar with research subject protection measures, yet not familiar with the informed consent process. This was especially surprising considering most participants have been asked to participate in research before, with slightly more than half having participated in research prior to our study. Most participants also believed that it is not necessary to examine "new" drugs before implemented in experiments. These findings are relevant for researchers to improve participant care by explaining the principles of informed consent (describing the intervention, emphasizing the patient's role in decision-making, discussing alternatives to the proposed intervention, and discussing the risks of the intervention) and educating participants on ethical implications of examining drugs before implementing them in studies [38]. Although most participants had positive attitudes to participating in research themselves or having a family member participate, most also had positive attitudes with reservations regarding research with human subjects. Although both groups did not have a preference in assignment to treatment versus non-treatment, more AA had positive attitudes towards random assignment compared to Whites, perhaps because random assignment decreases confounding variables in a study, such as racial discrimination against minority participants [39]. Most participants had positive attitudes regarding the scientists' motivations to do research, except for scientists' desire to minimize total expenses in treatment, suggesting that participants believe medical professionals are contributing to the cost crisis in healthcare [40]. 
Table 3 Performance on PABRQ between groups ${ }^{\mathrm{a}}$

\begin{tabular}{|c|c|c|c|c|}
\hline $\begin{array}{l}\text { Beliefs } \\
\text { Characteristics }^{\mathrm{b}}\end{array}$ & $\begin{array}{l}\text { African } \\
\text { American } \\
(n=46) \\
\mathrm{N}(\%)\end{array}$ & $\begin{array}{l}\text { White } \\
(n=60) \\
\mathrm{N}(\%)\end{array}$ & $\begin{array}{l}\text { Odds Ratios: White vs. African } \\
\text { American }\end{array}$ & $\begin{array}{l}P \\
\text { values }\end{array}$ \\
\hline Q1: Familiarity with informed consent processes? & & & $0.91(0.18,4.67)$ & 0.912 \\
\hline $\begin{array}{l}\text { Not familiar }(1,2) \\
\text { Generally familiar }(3,4,5)\end{array}$ & $\begin{array}{l}24(83) \\
5(17)\end{array}$ & $\begin{array}{l}35(85) \\
6(15)\end{array}$ & & \\
\hline Q2: Familiarity with research subject protection measures? & & & $0.45(0.14,1.38)$ & 0.17 \\
\hline $\begin{array}{l}\text { Not familiar }(1,2) \\
\text { Generally familiar }(3,4,5)\end{array}$ & $\begin{array}{l}9(30) \\
21(70)\end{array}$ & $\begin{array}{l}19(45) \\
23(55)\end{array}$ & & \\
\hline Q3: Were you ever asked to participate in research? & & & $0.53(0.16,1.68)$ & 0.289 \\
\hline $\begin{array}{l}\text { No } \\
\text { Yes }\end{array}$ & $\begin{array}{l}10(32) \\
21(68)\end{array}$ & $\begin{array}{l}15(37) \\
26(63)\end{array}$ & & \\
\hline Q4: Have you ever participated in research? & & & $0.93(0.31,2.77)$ & 0.890 \\
\hline $\begin{array}{l}\text { No } \\
\text { Yes }\end{array}$ & $\begin{array}{l}14(47) \\
16(53)\end{array}$ & $\begin{array}{l}18(44) \\
23(56)\end{array}$ & & \\
\hline Q5: Attitude towards research with human participants? & & & $0.46(0.11,1.72)$ & 0.251 \\
\hline $\begin{array}{l}\text { Positive with reservations }(3) \\
\text { Positive }(4,5)\end{array}$ & $\begin{array}{l}23(74) \\
8(26)\end{array}$ & $\begin{array}{l}36(86) \\
6(14)\end{array}$ & & \\
\hline Q6: Attitude towards participating in research yourself? & & & $0.99(0.07,11.85)$ & 0.996 \\
\hline $\begin{array}{l}\text { Negative } \\
\text { Positive }\end{array}$ & $\begin{array}{l}2(6) \\
29(94)\end{array}$ & $\begin{array}{l}2(5) \\
39(95)\end{array}$ & & \\
\hline $\begin{array}{l}\text { Q7: Attitude towards someone in family/close friend } \\
\text { participating in human research? }\end{array}$ & & & $0.84(0.13,5.17)$ & 0.855 \\
\hline Negative & $3(10)$ & $4(10)$ & & \\
\hline Positive & $28(90)$ & $37(90)$ & & \\
\hline Q8: Attitude towards random assignment? & & & $0.69(0.22,2.12)$ & 0.518 \\
\hline $\begin{array}{l}\text { Negative } \\
\text { Positive }\end{array}$ & $\begin{array}{l}9(29) \\
22(71)\end{array}$ & $\begin{array}{l}18(44) \\
23(56)\end{array}$ & & \\
\hline Q9: Opinion of participants being assigned to treatment vs. non-treatment? & & & $1.1(0.37,3.28)$ & 0.859 \\
\hline $\begin{array}{l}\text { Negative } \\
\text { Positive }\end{array}$ & $\begin{array}{l}13(42) \\
18(58)\end{array}$ & $\begin{array}{l}18(43) \\
24(57)\end{array}$ & & \\
\hline $\begin{array}{l}\text { Q10: Is it necessary to examine "new" drugs using science/ experiments before } \\
\text { they are implemented? }\end{array}$ & & & $1.87(0.57,6.61)$ & 0.313 \\
\hline Never or sometimes $(1,2,3)$ & $22(71)$ & $29(69)$ & & \\
\hline Always (4) & $9(29)$ & $13(31)$ & & \\
\hline \multicolumn{5}{|l|}{$\begin{array}{l}\text { Q11: What motives do you think scientists have to conduct } \\
\text { medical/clinical research (a-e): }\end{array}$} \\
\hline 11.a: The wish to find new treatments/examinations? & & & $0.82(0.19,3.32)$ & 0.776 \\
\hline $\begin{array}{l}\text { Important (3) } \\
\text { Very important (4) }\end{array}$ & $\begin{array}{l}7(23) \\
24(77)\end{array}$ & $\begin{array}{l}6(14) \\
36(86)\end{array}$ & & \\
\hline 11.b: The wish to help patients? & & & $0.61(0.17,2.04)$ & 0.425 \\
\hline $\begin{array}{l}\text { Slightly important }(2,3) \\
\text { Very important }(4)\end{array}$ & $\begin{array}{l}7(23) \\
24(77)\end{array}$ & $\begin{array}{l}11(26) \\
31(74)\end{array}$ & & \\
\hline 11.c: The wish to minimize total expenses in treatment/examination? & & & $0.62(0.19,1.93)$ & 0.408 \\
\hline $\begin{array}{l}\text { Not very important }(1,2,3) \\
\text { Very important }(4)\end{array}$ & $\begin{array}{l}19(61) \\
12(39)\end{array}$ & $\begin{array}{l}30(71) \\
12(29)\end{array}$ & & \\
\hline 11.d: The wish to promote their own career? & & & $0.57(0.19,1.7)$ & 0.316 \\
\hline $\begin{array}{l}\text { Not important }(1,2) \\
\text { Important }(3,4)\end{array}$ & $\begin{array}{l}15(48) \\
16(52)\end{array}$ & $\begin{array}{l}26(62) \\
16(38)\end{array}$ & & \\
\hline 11.e: The wish to increase knowledge generally? & & & $0.24(0.06,0.81)$ & $0.028 *$ \\
\hline Not very important $(2,3)$ & $7(23)$ & $17(40)$ & & \\
\hline Very important (4) & $24(77)$ & $26(60)$ & & \\
\hline
\end{tabular}

Frequency of different characteristics may vary, and percentages may not be equal to $100 \%$ because of missing data

${ }^{a}$ Logistic regression controlling for age, sex, and education compared odds ratios of AA and White participants

${ }^{\mathrm{b}}$ For each question, there is a range of answers that participants can choose from. Answers have been categorically dichotomized

*P values, obtained by Wald's test, indicate significant differences between AA and White groups at the 0.05 level 


\section{Limitations}

This study had several limitations. The smaller sample size means that the study is likely underpowered to determine some effects. Not all participants completed the PABRQ measure. Participants were recruited from the Atlanta metro geographical area. Therefore, the findings may not be generalizable to populations not in this specific geographical location. In addition, factors with possible relationships to poor health literacy performance like poor eyesight, sensory impairment, language barriers, and caregiver status were not measured, though we excluded participants with any significant illness [41]. Another issue is that while health literacy is modifiable, socioeconomic status is not. Therefore, more data collection and analysis related to socioeconomic status may have strengthened our findings. Also, REALM and S-TOFHLA measure different sub-domains; the tests do not consider if participants can understand the information presented in the measure. Other health literacy tools that measure additional facets of health literacy, such as individuals' ability to understand health information presented in the model effectively and teaching adults specific knowledge required to take care of themselves, could have been considered and may have led to different findings [42]. Lastly, individual financial barriers, such as the disproportionality of those minorities who are uninsured and underinsured, rise as an important factor to better understand the association between social determinants of health and health outcomes. The inaccessibility to insurance exists as a financial barrier due to the increasing cost of health coverage and results in limited access to doctors and treatments [4]. In this study, 36.5\% of AA and $63.5 \%$ of Whites were over the age of 65 , and thus on Medicare. For the remaining percentages of participants, the data is not available regarding their health insurance status. Future studies should include health insurance as a determinant influencing health outcomes and participation in research.

\section{Future Interventions}

In conclusion, we present evidence that AA individuals have poorer health literacy than White participants, but that both groups in our sample had similar attitudes and beliefs towards research. Care providers and researchers should thoroughly check for patients' understanding of potential risks and rights in a research study involving human participants by communicating clearly, confirming understanding, and educating participants prior to the start of the study [34]. Aging and minority communities play a significant role in improving methods for understanding health disparities and lack of research participation, especially regarding current-day world events like COVID-19 which result in substantially higher morbidity and mortality rates among both groups $[43,44]$. To more thoroughly examine the differential influence of beliefs towards participation and health literacy on attitudes in research by race, participants could be enrolled in an intervention to increase health literacy, such as the DREAMS
(Developing a Research participation Enhancement and Ádvocacy training progra $\underline{M}$ for diverse $\underline{\text { Seniors) }}$ program, which aims to increase knowledge about general health education to older adults from racially diverse and lower socioeconomic status and education backgrounds [29]. Researchers could then investigate the relationship of PABRQ measures between AA and White participants at pre- and post-intervention timepoints to observe if increasing health literacy will influence AA's beliefs about research compared to White participants.

Acknowledgments We acknowledge all participants in the DREAMS (Developing a Research participation Enhancement and Advocacy training prograM for diverse Seniors) program. This project was partially funded through a Patient-Centered Outcomes Research Institute (PCORI) Award (1099-EU). Additional support was provided from the National Parkinson Foundation (NPF) Community Grant (A-01). The authors also acknowledge all healthy participants from the DREAMS Team program. This study was made possible with support from the Parkinson's Foundation Grant (PFPLA-1706). The statements presented in this article do not necessarily represent the views of the Patient-Centered Outcomes Research Institute (PCORI), its Board of Governors or Methodology Committee but are solely the responsibility of the author(s).

Availability of Data and Material Data will be made available upon request.

Authors' Contributions All authors contributed to the study conception and design. Material preparation, data collection, and analysis were performed by Liang Ni, Allison A. Bay, and Madeleine E. Hackney. The first draft of this manuscript was written by Anjali Shah and Christiana Macauley and all authors commented on previous versions of the manuscript. All authors read and approved the final manuscript.

Funding Partial financial support was received from the Patient-Centered Outcomes Research Institute (PCORI) Award (1099-EU), the National Parkinson Foundation (NPF) Community Grant (A-01), and the Parkinson's Foundation Grant (PF-PLA-1706).

\section{Compliance with Ethical Standards}

Conflicts of Interest The authors declare that there are no conflicts of interest that are relevant to the content of this article.

Code Availability $\mathrm{R}$ code for data analysis will be made available upon request.

\section{References}

1. Davis TC, Arnold CL, Mills G, Miele L. A qualitative study exploring barriers and facilitators of enrolling underrepresented populations in clinical trials and biobanking. Front Cell Dev Biol. 2019;7. https://doi.org/10.3389/fcell.2019.00074.

2. Pampel FC, Krueger PM, Denney JT. Socioeconomic disparities in health behaviors. Annu Rev Sociol. 2010;36(1):349-70.

3. Williams DR, Mohammed SA, Leavell J, Collins C. Race, socioeconomic status, and health: complexities, ongoing challenges, and research opportunities. Ann N Y Acad Sci. 2010;1186(1):69-101.

4. Braveman PA, Cubbin C, Egerter S, Williams DR, Pamuk E. Socioeconomic disparities in health in the United States: what the patterns tell us. Am J Public Health. 2010;100:186-96. 
5. Sandefur GD, Campbell ME, Eggerling-Boeck J. Racial and ethnic identification, official classifications, and health disparities. In: Anderson NB, Bulatao RA, Cohen B, editors. Critical perspectives on racial and ethnic differences in health in late life. Washington, DC: The National Academies Press; 2004.

6. Darling-Hammond L. Unequal opportunity: race and education. The Brookings Review 1998. https://www.brookings.edu/articles/ unequal-opportunity-race-and-education/ Accessed $10 \mathrm{Feb} 2020$.

7. Nutbeam D. Health education and health promotion revisited. Health Educ J. 2018;78(6):705-9.

8. Jayasinghe UW, Harris MF, Parker SM, Litt J, van Driel M, Mazza D, et al. The impact of health literacy and life style risk factors on healthrelated quality of life of Australian patients. Health Qual Life Outcomes. 2016;14:68. https://doi.org/10.1186/s12955-016-0471-1.

9. DeWalt DA, Berkman ND, Sheridan S, Lohr KN, Pignone MP. Literacy and health outcomes. J Gen Intern Med. 2004;19:1228-39.

10. White S, Bennett I, Cordell T, Baxter SL. Health literacy of Americas adults: results from the 2003 National Assessment of Adult Literacy. PsycEXTRA Dataset. 2007. https://doi.org/10.1037/e530912012-001.

11. Cornett S. Assessing and Addressing Health Literacy. Online J Issues Nurs. 2009;14(3).

12. Hickey KT, Creber RM, Reading M, Sciacca RR, Riga TC, Frulla AP, et al. Low health literacy: implications for managing cardiac patients in practice. The Nurse Practitioner. 2018;43(8):49-55.

13. Benjamin RM. Improving health by improving health literacy. Public Health Rep. 2010;125(6):784-5.

14. Aaby A, Friis K, Christensen B, Rowlands G, Maindal HT. Health literacy is associated with health behaviour and self-reported health: a large population-based study in individuals with cardiovascular disease. Eur J Prev Cardiol. 2017;24:1880-8.

15. Santos RD. Better health literacy can make the difference when control of risk factors for cardiovascular disease and quality of life are concerned: European Journal of. Prev Cardiol. 2017;24(17):1878-9.

16. Freedman DA. Public Health Literacy. Qeios. 2019; https://doi.org/ $10.32388 / 196174$

17. Tolbert J, Orgera K, Singer N, Damico A. Key facts about the uninsured population. The Henry J. Kaiser Family Foundation. 2019. www.kff.org/uninsured/issue-brief/key-facts-about-theuninsured-population/. Accessed 15 Mar 2020.

18. Tamassia C, Lennon ML, Yamamoto K, Kirsch IS. Adult education in America: a first look at results from the adult education program and learner surveys. ETS Adult Education Program Study Report. 2007. https://www.ets.org/Media/Research/pdf/ETSLITERACY AEPS Report.pdf. Accessed 10 Feb 2020.

19. Andrulis DP, Brach C. Integrating literacy, culture, and language to improve health care quality for diverse populations. Am J Health Behav. 2007;31(1):122-33.

20. Ryan CL, Bauman K. Educational Attainment in the United States: 2015. U.S Census Bureau. 2016. https://www.census.gov/content/ dam/Census/library/publications/2016/demo/p20-578.pdf. Accessed 15 Mar 2020.

21. Perkins MM, Hart A, Dillard RL, Wincek RC, Jones DE, Hackney ME. A formative qualitative evaluation to inform implementation of a research participation enhancement and advocacy training program for diverse seniors: the DREAMS program. J Appl Gerontol. 2019;38:959-82.

22. Keyzer JF, Melnikow J, Kuppermann M, Birch S, Kuenneth C, Nuovo J, et al. Recruitment strategies for minority participation: challenges and cost lessons from the POWER interview. Ethn Dis. 2005;15:395-406.

23. UyBico SJ, Pavel S, Gross CP. Recruiting vulnerable populations into research: a systematic review of recruitment interventions. J Gen Intern Med. 2007;22:852-63.

24. Wilets I, O'Rourke M, Nassisi D. How patients and visitors to an urban emergency department view clinical research. Acad Emerg Med. 2003;10:1081-5.
25. Krzyzanowska MK, Kaplan R, Sullivan R. How may clinical research improve healthcare outcomes? Ann Oncol. 2011;22:vii10-5.

26. Pandya RE. A framework for engaging diverse communities in citizen science in the US. Front Ecol Environ. 2012;10:314-7.

27. Pinn VW. Achieving diversity and its benefits in clinical research. AMA J Ethics Am Med Assoc. 2004;6:561-5.

28. Bronfenbrenner U. Toward an experimental ecology of human development. Am Psychol. 1977;32(7):513-31.

29. Halpin SN, Dillard RL, Idler E, Clevenger C, Rothschild E, Blanton $\mathrm{S}$, et al. The benefits of being a senior mentor: cultivating resilience through the mentorship of health professions students. Gerontol Geriatr Educ. 2017;38(3):283-94.

30. Dillard RL, Perkins M, Hart A, Li C, Wincek R, Jones D, et al. Research advocacy training program benefits diverse older adults in participation, self-efficacy and attitudes toward research. Prog Community Health Partnersh. 2018;2(4):367-80.

31. Bass PF III, Wilson JF, Griffith CH. A shortened instrument for literacy screening. J Gen Intern Med. 2003;18(12):1036-8.

32. Baker DW, Williams MV, Parker RM, Gazmararian JA, Nurss J. Development of a brief test to measure functional health literacy. Patient Educ Couns. 1999;38(1):33-42.

33. Madsen SM, Mirza MR, Holm S, Hilsted KL, Kampmann K, Riis P. Attitudes towards clinical research amongst participants and nonparticipants. J Intern Med. 2002;251(2):156-68.

34. Scharff DP, Mathews KJ, Jackson P, Hoffsuemmer J, Martin E, Edwards D. More than Tuskegee: understanding mistrust about research participation. J Health Care Poor Underserved. 2010;21(3):879-97.

35. Kennedy B, Atske S. Science knowledge varies by race and ethnicity in U.S. Pew Research Center. 2019. https://www.pewresearch. org/fact-tank/2019/03/28/science-knowledge-varies-by-race-andethnicity-in-u-s/. Accessed 15 Mar 2020.

36. Shea JA, Beers BB, McDonald VJ, Quistberg DA, Ravenell KL, Asch DA. Assessing health literacy in African American and Caucasian adults: disparities in rapid estimate of adult literacy in medicine (REALM) scores. Fam Med. 2004;36(8):575-81.

37. Korver-Glenn E, Chan E, Ecklund EH. Perceptions of science education among African American and White evangelicals: a Texas case study. Rev Relig Res. 2015;57(1):131-48.

38. Shah P, Thornton I, Turrin D, Hipskind JE. Informed consent. Treasure Island, FL: StatPearls Publishing; 2020.

39. National Research Council. Measuring racial discrimination: panel on methods for assessing discrimination. Blank RM, Dabady M, Citro CF, editors. Washington, DC: The National Academies Press; 2004.

40. Kaplan RS, Porter ME. How to solve the cost crisis in health care. Harv Bus Rev. 2011;89(9):47-64.

41. Kirk JK, Grzywacz JG, Arcury TA, Ip EH, Nguyen HT, Bell RA, et al. Performance of health literacy tests among older adults with diabetes. J Gen Intern Med. 2012;27(5):534- 40.

42. Baker DW. The meaning and the measure of health literacy. J Gen Intern Med. 2006;21:878-83.

43. Kemenesi G, Kornya L, Tóth GE, Kurucz K, Zeghbib S, Somogyi BA, et al. Nursing homes and the elderly regarding the COVID-19 pandemic: situation report from Hungary. GeroScience. 2020:1-7.

44. Cyrus E, Clarke R, Hadley D, Bursac Z, Trepka MJ, Dévieux JG, et al. The impact of COVID-19 on African American communities in the United States. medRxiv. 2020. https://doi.org/10.1101/2020. 05.15.20096552.

Publisher's Note Springer Nature remains neutral with regard to jurisdictional claims in published maps and institutional affiliations. 